\title{
Association of Risk Factors with Coronary Angiographic Findings of Female Patients with Acute Myocardial Infarction at a Tertiary Hospital of Bangladesh
}

\author{
Jinnat Fatema Saira Safa ${ }^{1}$, A.K.M. Manzur Murshed ${ }^{2}$, Prabir Kumar Das ${ }^{2}$, Ashish Dey², \\ Biplob Bhattacharjee ${ }^{3}$, Anisul $\mathrm{Awal}^{3}$.
}

\begin{abstract}
::
Background: Coronary artery disease (CAD) is the leading cause of mortality and morbidity of women in developed and developing country. Although women in low and middle income countries have worse situation they are least studied. Cardiovascular risk factors assessment and their correlation with angiographic severity in female patients is essential to take preventive strategy and timely intervention.
\end{abstract}

Aim: The aim of this study was to evaluate the major risk factors of coronary artery disease and to study the relation of those cardiovascular risk factors with coronary angiographic findings in female patients with AMI .

Methods: This was a cross-sectional observational study carried out in the department of Cardiology, Chittagong Medical College Hospital (CMCH) from January 2017 to December 2017. One hundred and fifty consecutive female patients diagnosed as acute myocardial infarction (AMI) who subsequently underwent coronary angiography (CAG) during the study period were included in the study. Data regarding demographic, clinical \& laboratory features were recorded. Severity of CAG findings was assessed by Gensini score.

Results: The mean age of the study population was $53.19( \pm 10.71)$ years. Hypertension was the commonest cardiovascular risk factor $(\mathbf{7 8 \%})$ in this study followed by obesity $(68 \%)$, dyslipidaemia $(62 \%)$ and diabetes mellitus $(57.3 \%)$. About $80 \%$ patients had clustering of $\geq 3$ risk factors. Proportion of patients having STsegment elevation myocardial infarction (STEMI) and non ST-segment elevation myocardial infarction (NSTEMI) were $47 \%$ and $53 \%$ respectively. Thrombolytic was the most frequently used treatment modality for the management of STEMI patients. Double Vessel Disease, type B lesion with Gensini score $\geq \mathbf{2 0}$ were the most common CAG findings. Triple vessel disease and severe CAD (Gensini score $\geq 20$ ) were more in women with three or more risk factors. A significant $(p<0.05)$ linear correlation was found between Gensini score and age, triglyceride level and total cholesterol level. Other factors, including, obesity, family history, hypertension, diabetes mellitus, menopausal status were found to be more prevalent among severe coronary artery disease on CAG but the differences were not statistically significant $(p>0.05)$.

Conclusion: The present study showed a significant relation of having multiple cardiovascular risk factors with developing more aggressive angiographic findings. It also revealed that Bangladeshi female patients of AMI had clusters of cardiovascular risk factors and presence of multiple risk factors is a predictor of severe coronary artery disease.

Key words: Acute myocardial infarction; cardiovascular risk factors; female patients; Gensini score.

1. Assistant Professor, Department of Medicine, Chattagram Maa-Shishu-O-General Hospital,Chittagong, Bangladesh.

2. Associate professor and Head (Ex), Department of Cardiology, Chittagong Medical College, Chittagong, Bangladesh.

3. Assistant professor, Department of Cardiology, Chittagong Medical College, Chittagong, Bangladesh.

Address of Correspondence: Dr Jinnat Fatema Saira Safa, Assistant Professor, Department of Medicine, Chattagram Maa-Shishu-OGeneral Hospital, Chittagong, Bangladesh. Mobile: 01534545252, Email: jinnatcmc@yahoo.com

DOI: https://doi.org/10.3329/bhj.v34i2.44440

Copyright $\odot 2017$ Bangladesh Cardiac Society. Published by Bangladesh Cardiac Society. This is an Open Access articles published under the Creative Commons Attribution-NonCommercial 4.0 International License (CC BY-NC). This license permits use, distribution and reproduction in any medium, provided the original work is properly cited and is not used for commercial purposes. 


\section{Introduction:}

Cardiovascular disease is the leading cause of mortality for women in the United States and globally. Coronary artery disease (CAD) afflicts 6.6 million women of United States annually and remains the leading morbidity and mortality threat in women ${ }^{1}$. Women in low and middle income countries also have worse situation than men, experiencing higher proportion of CAD related deaths than men. South Asians are unduly prone to develop CAD. Of all South Asian countries, Bangladesh probably has the highest rates of cardiovascular disease (CVD) and yet is the least studied; in the global combat against CVD ${ }^{2}$.Women and men with coronary artery disease tend to differ in their presenting symptoms, access to investigations, treatment and overall prognosis ${ }^{3}$. Women with acute coronary syndrome (ACS) are generally older with more clustering of risk factors and

higher risk of mortality than men. Certain risk factors are more prevalent in women. These include type $2 \mathrm{DM}$, hypertension, obesity, depression, and other psychosocial risk factors. Diabetes mellitus is a stronger CAD risk factor in women than in men. Hypertension is associated with a two to threefold increased risk for CAD in women. In women, low levels of high density lipoprotein are strong predictors of higher CAD risk than high levels of low density lipoprotein. Obesity is a major risk factor for AMI in women and increases their risk almost 3fold.The risk of AMI associated with metabolic syndrome is higher in women ${ }^{4}$. Almost $50 \%$ of women have a clustering of $\geq 3$ metabolic risk factors for ischemic heart disease ${ }^{5}$. The pathophysiology of CAD varies between women and men. An interesting observation is that women with ACS have less extensive obstructive and more diffuse coronary artery disease compared with men, but the event rate in non obstructive coronary artery disease seems to be higher in women ${ }^{6-8}$. Despite the lack of obstructive CAD visualized on cardiac catheterization at the time of acute coronary syndrome (ACS), the prognosis of these women is not benign. Over one-half of symptomatic women without obstructive CAD continue to have signs and symptoms of ischemia and to undergo repeat hospitalization and coronary angiography ${ }^{9,10}$. Recently, disorders of the coronary microvasculature and endothelial dysfunction have been implicated in the occurrence of non-obstructive CAD in women $^{11}$. Historically fewer women than men have been included in studies on $\mathrm{CAD}^{12}$. Till date few data are available on coronary artery disease in female of our country as well. The consequence is that evidence base for several treatments is less firm. Closing this research gap sex-specific evaluation of coronary pathophysiology, optimum diagnostic strategies, effective lifestyle, pharmacological, and invasive interventions are required. So this study was designed to determine the major risk factors and their association with angiographic severity of coronary artery disease in female patients presenting with acute myocardial infarction.

\section{Materials and Methods:}

This is a hospital based cross-sectional observational study carried out in the department of Cardiology, Chittagong Medical College Hospital $(\mathrm{CMCH})$ from January 2017 to December 2017. One hundred and fifty consecutive female patients diagnosed as acute

myocardial infarction (AMI) according to third universal definition of myocardial Infarction ${ }^{13}$, who subsequently underwent coronary angiography (CAG) within 4 wks of AMI during the study period were included in the study. Patients with history of $\mathrm{PCl}$ or CABG, patients with valvular heart disease, patients unsuitable for coronary aniography and those refusing consent were excluded from the study. An informed written consent was taken from each study patient.

Demographic profile of the patient including age, occupation, economic status and major risk factors like hypertension, diabetes, dyslipidaemia, history of smoking/ tobacco abuse, family history of CAD and post menopausal status were recorded. Data regarding weight, height was recorded, BMI was calculated. Patients having $\mathrm{BMI} \geq 25 \mathrm{Kg} / \mathrm{m}^{2}$ were considered as obese according to World Health Organization (WHO ${ }^{14}$ criteria. Smoker were those who gave history of previous or current smoking of cigarettes, cigars, pipes and chewing tobacco ${ }^{15}$. Patients who gave family history of any direct blood relatives (parents, siblings, children) having either angina, $\mathrm{Ml}$ or sudden cardiac death without obvious cause at age $<50$ yrs for men and $<55$ yrs for women were recorded as having positive family history ${ }^{15}$.

Blood pressure was measured twice in sitting position in both arms and higher one was taken as recorded blood pressure. Patients who were previously diagnosed as hypertensive and taking antihypertensive or those with raised blood pressure $\geq 140 / 90 \mathrm{~mm}$ of $\mathrm{Hg}$ measured twice were considered as hypertensive according to The Seventh Report of the Joint National Committee on Prevention, Detection, Evaluation and Treatment of High Blood Pressure 16. Random plasma glucose and lipid profile within $24 \mathrm{hrs}$ of AMI were measured. Fasting blood glucose, $2 \mathrm{hrs}$ post prandial blood glucose and $\mathrm{Hb}$ A1C were done on the following day. Diabetic patients were those who met American Diabetic Association(ADA) 
criteria $^{17}$ or those already on antidiabetic drug. Dyslipidaemia was diagnosed according to National Cholesterol Education Program (NCEP) criteria $^{18}$ or those on lipid lowering agent. Other routine hematological (complete blood count) and biochemical investigation (serum creatinine) and echocardiography were done.

Coronary angiography was performed through standard femoral or radial artery approach. Angiographic data was collected by analyzing the angiogram. The origin and course of three major vessels and their branches were analysed in at least two different planes. Coronary artery disease, defined as epicardial coronary segment with stenosis $>50 \%$ was diagnosed visually and confirmed in multiple projections and orthogonal views. Patients was grouped as having single vessels disease (SVD), double vessel disease (DVD) and triple vessel disease (TVD) according to the number of vessel involvement. Patients were also grouped according to the type of lesions involved. Atherosclerotic lesion complexity was categorized according to the Joint American College of Cardiology/American Heart Association (ACC/AHA) taskforce classification system ${ }^{19}$ ( type A, type B, type C).

Severity of stenosis was assessed by Gensini score 20; It grades narrowing of the lumen of the coronary artery and scores it with numerical values with the following method; score 1 for $1-25 \%$ narrowing, 2 for $26-50 \%$ narrowing, 4 for $51-75 \%, 8$ for $76-90 \%, 16$ for $91-99 \%$, and 32 for a completely occluded artery. This score is then multiplied by a factor that represents the importance of the lesion's location in the coronary artery system: 5 for the left main coronary artery; 2.5 for the proximal left anterior descending coronary artery or proximal circumflex artery; 1.5 for the mid left anterior descending coronary artery; 1 for the right coronary artery, distal left anterior descending coronary artery, obtuse marginal artery or posterior lateral artery; and 0.5 for other stenosis. The severity of disease is expressed as the sum of the scores for the individual lesions. By definition, a Gensini score of 20 or more was considered to be severe CAD. Measurement data was repeated twice by the same operator and the mean value was the final data. Shimadzu Bransist alexa was the fluoroscopic machine used in our cathlab.

\section{Statistical analysis}

The statistical analysis was carried out by using Statistical Package for Social Sciences (SPSS -23). Quantitative or continuous variables were described as mean \pm standard deviation. Comparison between means of two groups was done by using Student's t-test.
Qualitative or categorical variables were described as frequencies and proportions. Proportions were compared using chi-square. Correlation analysis was done by Pearson's correlation coefficient test. Correlation of anthropometric variables and severity of angiogram findings in different groups was determined using correlation coefficient and linear regression analysis. Logistic regression analysis was performed to determine the independent predictor of CAD. Statistical significance and confidence interval were set at $p<0.05$ and $95 \%$ level respectively.

\section{Results:}

Among 150 female patients mean ( \pm SD) age of the study women was $53.19( \pm 10.71)$ years and majority of them were $>40$ years of age. Demographic characteristics of the study population are described in Table I.

The prevalence of different CAD risk factors among the study population are descrived in Table II. Mostly prevalent risk factor was hypertriglyceridaemia, followed by hypertension, obesity (by BMI), DM and postmenopausal state.

Coronary angiogram findings of the study population are summarized in Table: III with respect to number of coronary vessel involved, location and type of involved vessel and the severity category by Gensini score.

Table IV shows the association of different risk factors with the number of coronary vessel involved. Double vessel disease was more frequent among the study population followed by single vessel and triple vessel disease.

Clustering of the conventional CVD risk factors (smoking, hypertension, family history of CAD, DM, dyslipidaemia, and obesity) among the study population are presented in Figure:1. It shows that seventy percent of patients had

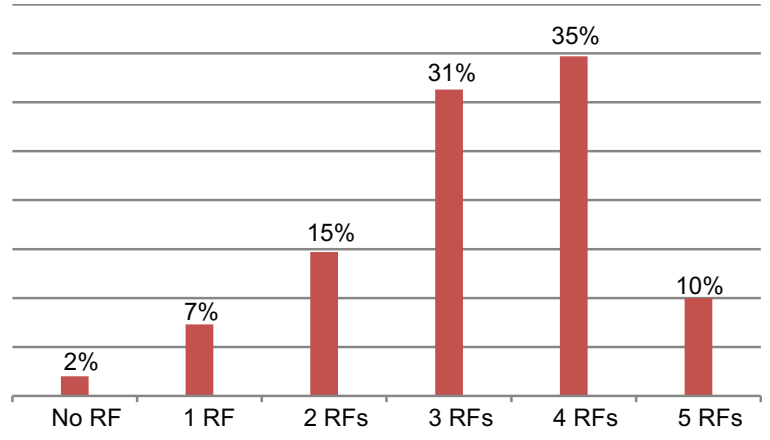

Fig.-1: Clustering of risk factors among the study population 
Table-I

Demographic characteristics of the study subjects

\begin{tabular}{|c|c|c|}
\hline Characteristics & $\begin{array}{c}\text { Frequency } \\
\text { (n) }\end{array}$ & $\begin{array}{c}\text { Percentage } \\
(\%)\end{array}$ \\
\hline \multicolumn{3}{|l|}{ Age, years } \\
\hline Mean \pm SD & & \\
\hline$\leq 55$ years & 75 & 50 \\
\hline$>55$ years & 75 & 50 \\
\hline \multicolumn{3}{|l|}{$\mathrm{BMI}, \mathrm{kg} / \mathrm{m}^{2}$} \\
\hline Mean $\pm S D$ & & \\
\hline Normal weight (18.5-22.9) & 48 & 32.0 \\
\hline Over weight (23-24.9) & 37 & 24.7 \\
\hline Obese $(>25)$ & 65 & 43.3 \\
\hline
\end{tabular}

Data are presented as frequency $(\mathrm{n})$ and percentage $(\%)$ or mean $\pm \mathrm{SD}$

Table-II

Distribution of the study subjects by risk factors of CAD

\begin{tabular}{|c|c|c|}
\hline Risk factors & $\begin{array}{l}\text { Frequency } \\
\text { (n) }\end{array}$ & $\begin{array}{c}\text { Percentage } \\
(\%)\end{array}$ \\
\hline \multicolumn{3}{|l|}{ Hypertension } \\
\hline Yes & 117 & 78.0 \\
\hline No & 33 & 22.0 \\
\hline \multicolumn{3}{|l|}{ Diabetes ${ }^{c \&}$} \\
\hline Yes & 86 & 57.3 \\
\hline No & 64 & 42.7 \\
\hline \multicolumn{3}{|l|}{ Menopause } \\
\hline Postmenopausal & 85 & 56.7 \\
\hline Premenopausal & 65 & 43.3 \\
\hline \multicolumn{3}{|l|}{$\mathrm{BMI} \geq 25 \mathrm{~kg} / \mathrm{m}^{2}$} \\
\hline Yes & 102 & 68.0 \\
\hline No & 48 & 32.0 \\
\hline \multicolumn{3}{|l|}{ Dyslipidemia* } \\
\hline Yes & 93 & 62.0 \\
\hline No & 57 & 38.0 \\
\hline \multicolumn{3}{|l|}{ Total Cholesterol mg/dl } \\
\hline Normal $(<200 \mathrm{mg} / \mathrm{dl})$ & 96 & 64.0 \\
\hline Hypercholesterolaemia (e"200mg/dl) & 54 & 36.0 \\
\hline \multicolumn{3}{|l|}{ Triglyceride, $\mathrm{mg} / \mathrm{dl}$} \\
\hline Normal $(<150 \mathrm{mg} / \mathrm{dl})$ & 6 & 4.0 \\
\hline Hyper TG ( $\geq 150 \mathrm{mg} / \mathrm{dl})$ & 144 & 96.0 \\
\hline \multicolumn{3}{|l|}{ High density lipoprotein level, mg/dl } \\
\hline Low HDL $(<40 \mathrm{mg} / \mathrm{dl})$ & 91 & 60.7 \\
\hline Normal HDL ( $\geq 40 \mathrm{mg} / \mathrm{dl})$ & 59 & 39.3 \\
\hline \multicolumn{3}{|l|}{ Low density lipoprotein level, mg/dl } \\
\hline Normal $(<130 \mathrm{mg} / \mathrm{dl})$ & 132 & 88.0 \\
\hline High LDL ( $\geq 130 \mathrm{mg} / \mathrm{dl})$ & 18 & 12.0 \\
\hline
\end{tabular}

Data are presented as mean \pm SD or frequency $(n)$ and percentage $(\%)$

${ }^{c \&} \mathrm{H} / \mathrm{O}$ DM or having IGT; * H/O dyslipidaemia or having abnormal Cholesterol/LDL/HDL 
three or more risk factors. The more commonly occurred risk factors in cluster were hypertension, dyslipidaemia, diabetes and obesity in different combination. Only three patients $(2 \%)$ were free from all of the above mentioned risk factors. Two third of the study population $(70 \%)$ had three or more risk factors.

Table: $\mathrm{V}$ shows that triple vessel disease and severe CAD (Gensini score $\geq 20$ ) were significantly more prevalent among the women with three or more risk factors $(p<0.05)$.

Association of different CVD risk factors with type of involved coronary artery lesions in CAG are described in Table VI.

Irrespective of the type of risk factors Type B lesion was the most prevalent lesion type. However, statistically significant difference was found only with smoking and type of lesion $(p<0.05)$. Severity of coronary artery disease was done by Gensini score. Score $<20$ was considered as not severe CAD and score $\geq 20$ as severe CAD.
Table VIII presents the association between Gensini score and risk factors. It revealed that odds of having severe CAD increased among the subjects who had risk factors. But, statistically significant difference $(p<0.05)$ was present for smoking, age more than 55years and dyslipidaemia.

Spearman's correlation analyses were performed for variables- age, RBS, TG, total cholesterol, HDL-c, LDL-C and BMI. BMI and HDL-C showed negative correlation and other risk factors showed positive correlation with Gensini score (Table VIII).

Some of the variables proved to have association with the severity of CAG findings (Gensini score $\geq 20$ ) are included as independent variables in the logistic regression analysis demonstrated in Table IX. The result revealed that age, and dyslipidaemia are working independently on development of severe CAD finding by Gensini score.

Table-III

Nature and severity of CAG findings

\begin{tabular}{lcc}
\hline Parameters & $\begin{array}{c}\text { Frequency } \\
(\mathrm{n})\end{array}$ & $\begin{array}{c}\text { Percentage } \\
(\%)\end{array}$ \\
\hline No. of vessel involved & & \\
Single vessel & 52 & 34.7 \\
Double vessel & 62 & 42.7 \\
Triple vessel & 34 & 22.6 \\
Location of vessel involvement & & \\
LAD & 27 & 18.0 \\
LCX & 11 & 7.3 \\
RCA & 10 & 6.7 \\
LAD+RCA & 39 & 26.0 \\
LCX+RCA & 6 & 4.0 \\
LAD+LCX+RCA & 34 & 22.7 \\
OM 2 & 4 & 2.7 \\
LAD + Rami & 4 & 2.7 \\
Lt main+LAD & 5 & 3.3 \\
LAD+LCX & 10 & 6.7 \\
Type of lesion & & \\
TypeA & 26 & 17.3 \\
Type B & 104 & 69.3 \\
Type C & 20 & 13.3 \\
Gensini score & & \\
Non critical CAD $(<20)$ & 37 & 24.7 \\
Severe CAD $(\geq 20)$ & 113 & 75.3 \\
\hline
\end{tabular}

Data are presented as frequency (n) and percentage (\%) 
Table-IV

Risk factors in relation to number of coronary artery involved

\begin{tabular}{|c|c|c|c|c|c|c|c|}
\hline \multirow[t]{2}{*}{ Risk factors } & \multicolumn{2}{|c|}{ Single vessel } & \multicolumn{2}{|c|}{ Double vessel } & \multicolumn{2}{|c|}{ Triple vessel } & \multirow[t]{2}{*}{$P$ value } \\
\hline & (n) & $(\%)$ & (n) & $(\%)$ & $(n)$ & $(\%)$ & \\
\hline Age, $>55$ years & 31 & 41.3 & 37 & 49.3 & 7 & 9.3 & $0.001^{*}$ \\
\hline $\mathrm{H} / \mathrm{O}$ Smoking & 2 & 18.2 & 6 & 54.4 & 3 & 27.3 & $0.454^{\dagger}$ \\
\hline Family H/O CAD & 13 & 28.3 & 24 & 52.2 & 9 & 19.6 & $0.292^{\dagger}$ \\
\hline Postmenopausal & 26 & 30.6 & 35 & 41.2 & 24 & 28.2 & $0.155^{\dagger}$ \\
\hline Hypertension & 32 & 27.4 & 52 & 45.3 & 32 & 27.4 & $0.001^{*}$ \\
\hline DM & 31 & 36.0 & 31 & 36.0 & 24 & 28.0 & $0.69^{\dagger}$ \\
\hline Dyslipidaemia & 31 & 33.3 & 37 & 39.8 & 25 & 26.9 & $0.248^{\dagger}$ \\
\hline Obesity & 34 & 33.2 & 40 & 39.2 & 28 & 17.5 & $0.118^{\dagger}$ \\
\hline
\end{tabular}

Data are presented as frequency $(n)$ and percentage (\%);

*Significant by Chi-square test;

${ }^{\dagger}$ Not significant by Chi-square test

Table-V

Relation of risk factors clustering with CAG findings of study population

\begin{tabular}{ccccccc}
\hline Characteristics & \multicolumn{2}{c}{$<3$ R. F. } & & \multicolumn{2}{c}{$\geq 3$ R. F. } & P value \\
\cline { 2 - 3 } & $(\mathrm{n})$ & $(\%)$ & & $(\mathrm{n})$ & $(\%)$ & \\
\hline Subtypes of Ml & & & & & \\
NSTMI $(\mathrm{n}=79)$ & 23 & 29.1 & & 56 & 70.9 & $0.122^{\dagger}$ \\
STMI $(\mathrm{n}=71)$ & 13 & 18.3 & & 58 & 81.7 & \\
Inferior MI & 6 & 15.8 & & 32 & 84.2 & $0.552^{\dagger}$ \\
Anterior MI & 7 & 21.2 & & 26 & 78.8 &
\end{tabular}

No. of vessel involved

$\begin{array}{lccccc}\text { Single vessel } & 12 & 23.1 & 40 & 76.9 & \\ \text { Double vessel } & 22 & 34.4 & 42 & 76.5 & 0.001^{*} \\ \text { Triple vessel } & 2 & 5.9 & 32 & 94.1 & \end{array}$

Type of lesion in involved vessels

$\begin{array}{lccccc}\text { Type A } & 8 & 30.8 & 18 & 69.2 & \\ \text { Type B } & 26 & 25.0 & 78 & 75.0 & 0.239^{\dagger} \\ \text { Type C } & 2 & 10.0 & 18 & 90.0 & \\ & & & & & \\ \text { nsini score } & & & & & 0.023^{*} \\ \text { Non critical CAD }(<20) & 14 & 37.8 & 33 & 62.2 & \\ \text { Severe CAD }(\geq 20) & 22 & 19.5 & 91 & 80.5 & \end{array}$

Data are presented as frequency $(\mathrm{n})$ and percentage (\%);

*Significant by Chi-square test;

${ }^{\dagger}$ Not significant by Chi-square test 
Table-VI

Type of coronary artery lesion with respect to risk factors Lesion type

\begin{tabular}{|c|c|c|c|c|c|c|c|}
\hline \multirow[t]{2}{*}{ Risk factors } & \multicolumn{2}{|c|}{ Type A } & \multicolumn{2}{|c|}{ Type B } & \multicolumn{2}{|c|}{ Type C } & \multirow[t]{2}{*}{$P$ value } \\
\hline & $\mathrm{N}$ & $\%$ & $\mathrm{~N}$ & $\%$ & $\mathrm{~N}$ & $\%$ & \\
\hline Smoking & 0 & 0.0 & 11 & 100 & 0 & 0.0 & $0.012^{*}$ \\
\hline Hypertension & 20 & 17.1 & 81 & 69.2 & 16 & 13.7 & $0.968^{\dagger}$ \\
\hline DM & 15 & 17.4 & 55 & 64.1 & 16 & 18.6 & $0.080^{\dagger}$ \\
\hline $\mathrm{F} / \mathrm{H}$ of $\mathrm{CAD}$ & 8 & 17.4 & 36 & 78.3 & 2 & 4.3 & $0.092^{\dagger}$ \\
\hline Postmenopausal & 14 & 16.5 & 59 & 69.4 & 12 & 14.1 & $0.961^{\dagger}$ \\
\hline Age $>40$ years & 22 & 16.4 & 94 & 70.1 & 18 & 13.4 & $0.692^{\dagger}$ \\
\hline Dyslipidaemia & 18 & 15.4 & 81 & 69.2 & 18 & 15.3 & $0.241 \dagger$ \\
\hline
\end{tabular}

Data are presented as frequency $(n)$ and percentage (\%);

${ }^{*}$ Significant by Chi-square test; ${ }^{\dagger}$ Not significant by Chi-square test.

Table-VII

Association between Gensini score and risk factors

\begin{tabular}{|c|c|c|c|c|c|c|}
\hline \multirow[t]{2}{*}{ Risk factors } & \multicolumn{2}{|c|}{ Non critical CAD (score <20) } & \multicolumn{2}{|c|}{ Severe CAD (Score $\geq 20)$} & \multirow[t]{2}{*}{ Odds ratio } & \multirow[t]{2}{*}{$P$ value } \\
\hline & (n) & $(\%)$ & (n) & $(\%)$ & & \\
\hline Age, $>55$ years & 11 & 14.7 & 64 & 85.3 & 3.08 & $0.004^{*}$ \\
\hline $\mathrm{H} / \mathrm{O}$ Smoking & 0 & 0.0 & 11 & 100.0 & 6.51 & $0.040^{*}$ \\
\hline Family H/O CAD & 11 & 23.9 & 35 & 76.1 & 1.09 & $0.18^{\dagger}$ \\
\hline Postmenopausal & 21 & 24.7 & 64 & 75.3 & 0.99 & $0.99^{\dagger}$ \\
\hline Hypertension & 25 & 21.4 & 92 & 78.6 & 2.10 & $0.078^{\dagger}$ \\
\hline DM & 18 & 20.9 & 68 & 79.1 & 1.59 & $0.218^{\dagger}$ \\
\hline Dyslipidaemia & 15 & 16.1 & 78 & 83.9 & 9.39 & $0.002^{*}$ \\
\hline Obesity & 21 & 20.6 & 81 & 79.4 & 1.93 & $0.09^{\dagger}$ \\
\hline
\end{tabular}

Data are presented as frequency $(\mathrm{n})$ and percentage (\%);

*Significant by Chi-square test;

${ }^{\dagger}$ Not significant by Chi-square test.

Table-VIII

Spearman's correlation analysis for Gensini score with independent variables

\begin{tabular}{lcc}
\hline Independent variables & R (Correlation coefficient) & P value \\
\hline Age in completed years & 0.307 & $<0.001^{*}$ \\
Random blood glucose, mg/dl & 0.128 & $0.118^{\dagger}$ \\
Total cholesterol level, mg/dl & 0.195 & $0.017^{*}$ \\
Triglyceride level, mg/dl & 0.221 & $0.007^{*}$ \\
High density lipoprotein level, mg/dl & -0.099 & $0.228^{\dagger}$ \\
Low density lipoprotein, mg/dl & 0.159 & $0.053^{\dagger}$ \\
BMl, $\mathrm{kg} / \mathrm{m}^{2}$ & -0.048 & $0.562^{\dagger}$ \\
\hline
\end{tabular}

${ }^{*}$ Indicate significant correlation at $.05 \%$ level.

t: Not significant at $0.05 \%$ level 
Table-IX

Multivariate analysis (logistic regression) with severity of CAD (Gensini score $\geq 20$ ) as dependent variable and other risk factors of $C A D$ as independent variables

\begin{tabular}{lccc}
\hline Variables & Adjusted odds ratio & 95\% confidence interval & P value \\
\hline Age & 1.15 & $1.045-1.89$ & $0.001^{*}$ \\
Hypertension & 1.88 & $0.68-516$ & $0.221^{\dagger}$ \\
Diabetes mellitus & 1.02 & $0.427-2.43$ & $0.967^{\dagger}$ \\
Family H/O CAD & 0.52 & $0.189-1.41$ & $0.196^{\dagger}$ \\
Post menopausal status & 2.86 & $0.099-5.45$ & $0.101^{\dagger}$ \\
Dyslipidaemia & 3.66 & $1.416-9.45$ & $0.007^{*}$ \\
Obesity & 2.14 & $0.869-5.28$ & $0.098^{\dagger}$ \\
\hline
\end{tabular}

*Indicate significant association at $.05 \%$ level.

†Not significant

\section{Discussion:}

Women's heart health is not solely a medical issue but also involves economic, psychosocial, cultural, environmental, community, health system, political and public policy issues locally and globally. Cardiovascular disease is the number one killer of women in both developed and developing countries. Like other South Asian countries prevalence of coronary artery disease is increasing in Bangladesh. There is few data regarding coronary artery disease in our country and study among female patients with coronary artery disease is scarce. In our study we wanted to explore whether the traditional CAD risk factors in female patients with MI, like Diabetes mellitus, hypertension, smoking/ tobacco abuse, advancing age, dyslipidaemia, obesity, family history of coronary artery disease correlate with the severity of coronary atherosclerosis detected by coronary angiography as they are well recognized for their association with clinical events and acute coronary syndromes. A number of scores have been described in the past for grading the severity of coronary artery disease on angiography like Genisini score, Jenkins score and Friesingers score. We used the Genisini scoring system for assessing the coronary atherosclerotic disease burden. We chose this because of its simplicity and Genisini score is widely accepted as a CAD burden marker and its prognostic value has been demonstrated in different clinical situations. We included female MI patients only and divided the study population into two groups depending upon the Gensini score, score $<20$ and score $\geq 20$. Traditional cardiac risk factors are highly prevalent in women of our study and clustering of CAD risk factors is positively associated with severe coronary artery disease as assessed by Gensini score.
The mean age of the study population was $53.19( \pm 10.71)$ years. A Global case-control study of risk factors for cases of acute myocardial infarction reported that the mean age (51.9 years) for the occurrence AMI among Bangladeshi population was the lowest amongst all South Asians and it was 6 years lower compared with non-South Asians (58.8 years) ${ }^{21}$. In a Hospital based study in India the demographic profile of the study population (Female patients with acute myocardial infarction) revealed the mean age $62.74 \pm 13.6$ years, which is higher than our study 22 . Western studies have reported mean age higher as compared to other studies conducted in this region such as study by Chang et al. (73 years) ${ }^{23}$. Age was recorded through direct interviewing of the patient without

cross checking any certificate and vital statistics recording system in Bangladesh is weak. So, this demographic data might be lack of some internal and external validity. Logistic regression shows that age is working on CAD severity independently from others factors including in the model. Women with severe CAD (Gensini score $\geq 20$ ) tend to be older with mean age 54.74 years in our study. Many studies are in line with our results and showed that advancing age is a risk factors of CAD in women ${ }^{24}$.

Out of 150 female patients Diabetes was present in $86(57.3 \%)$ patients, hypertension was present in $117(78 \%)$ patients, dyslipidaemia in $93(62 \%)$, obesity in $102(68 \%)$, family history of IHD was present in $46(30.7 \%)$ and $11(7.3 \%)$ patients were smokers.

Among the conventional CAD risk factors, smoking was distinctly very low and it is in agreement with other study held in our neighboring country ${ }^{6}$. Cultural disapproval 
prohibits women from smoking in Bangladesh. In our study significant association was seen between the smoking/tobacco abuse and severity of coronary artery disease.

Prevalence of hypertension and diabetes was very high in our study population. The same finding was reported by Wenger where prevalence of hypertension was $65 \%$ 4. Diabetes mellitus is the most important risk factor for $C A D$, the presence of diabetes in women increasing CAD risk by $3-7$ folds compared to $2-3$ folds increase in diabetic men ${ }^{17}$. In our study, diabetes was four times higher in women with severe CAD (Gensini score $\geq 20$ ) compared with less severe CAD. In addition, different study showed that women with diabetes have a greater than threefold increase in CAD risk than non-diabetic women, and CAD mortality in women is $3-5$ times higher in diabetic compared to non-diabetic and 3-fold higher relative risk for all cardiovascular mortality in women compared with men ${ }^{26}$. These two risk factors were found in Palestinian study in 2013 in patients with CAD that showed high prevalence of hypertension and diabetes in women $74.3 \%, 65.7 \%$ respectively 27 .

Regarding the obesity, the majorities of our study population (43.3) are obese and has BMI more than 25 $\mathrm{kg} / \mathrm{m}^{2}$, and obese women are at higher risk for severe CAD than overweight but the differences were not statistically significant. Many studies are in line with our results and showed that obesity increased the risk of CAD. In United state (USA), $22 \%$ to $37 \%$ of women are obese (BMI > 30), and $7 \%$ having a $\mathrm{BMI} \geq 40 \mathrm{~kg} / \mathrm{m} 2$, increase weight is positively associated with increase CAD risk and mortality in women ${ }^{28}$. In the Framingham heart study, obesity increases the risk of CAD by $64 \%$ in women, as opposed to $46 \%$ in male ${ }^{6}$.

Family history of CAD was present in 46 patients. Similar finding was observed in other studies. A family history of premature IHD in a sister carries 12fold higher risk for IHD in comparison to six fold for a brother and three fold for a parent ${ }^{15}$.

Risk factors which is unique for women such as menopause; our data showed that $56.7 \%$ of study population was menopaused and the prevalence of severe CAD was higher this

group. Controlling for age by logistic regression reduces the role of menopause as risk factors for CAD and kept age as the main risk factor.

Evaluation of the frequency of cardiovascular risk factors in the study population revealed that hypertension, obesity, dyslipidaemia and diabetes were the most prevalent risk factors $(78 \%, 68 \%, 62 \%$ and $57.3 \%$ respectively). Hypertension, dyslipidaemia, diabetes and obesity were the more commonly found risk factors in cluster. High TG was the most common abnormality found in this study (96\%). The frequency of patients with HDL-C and LDL-C in the dyslipidaemic range was $60.7 \%$ and $12 \%$ respectively. Thirty six percent patients had hyprecholesterolaemia. Dyslipidaemia as a risk factor was higher when compared with the finding of Chang et al. $(18.7 \%)^{23}$.

We demonstrated a significant linear correlation between severity of coronary artery disease as assessed by Gensini score and age, TG level and cholesterol level, suggesting that as the age, TG level and total cholesterol level increases, the severity of coronary artery disease will increase with multiple and complex lesions. Regarding the type of CAG findings in relation to number of risk factors, there was a statistically significant difference between patients having $<3$ risk factors and those having $\geq 3$ risk factors in relation to number of vessel involved $(p<0.05)$. Triple vessel disease, diffuse character of lesions, and left ventricle dysfunction were mostly evident in patients having $\geq 3$ risk factors. This result means that these severe angiographic characters are clearly linked to multiple \& clustering risk factors. Gera $\mathrm{S}$ et al. ${ }^{29}$ showed that there is a positive association of two and three vessels disease with having $\geq 3$ risk factors similar to our study findings.

\section{Limitations:}

This study had the limitations that study was conducted in a single center, study population was relatively small, study was observational non-randomized and might be subjected to selection bias and major traditional risk factors were seen here, other possible emerging risk factors were not looked for.

\section{Conclusion:}

This study showed a significant relation of having multiple cardiovascular risk factors with developing more aggressive angiographic findings in female. It also revealed that Bangladeshi female patients of AMI had clusters of cardiovascular risk factors and presence of multiple risk factors is a predictor of severe coronary artery disease. Further large scale studies are needed to verify our results and to determine the independent influences of individual risk factor and to investigate the role of other hidden risk factors in Bangladeshi female patients with myocardial infarction. 


\section{References:}

1. Mozaffarian D, Benjamin EJ, Go AS, Arnett DK, Blaha $\mathrm{MJ}$, Cushman $\mathrm{M}$ et al. Heart disease and stroke statistics-2015 update: a report from the American Heart Association. Circulation. 2015;131:29-322.

2. Sayeed MA, Mahtab H, Sayeed S, et al. Prevalence and risk factors of coronary Heart disease in a rural population of Bangladesh. Ibrahim Med Coll J. 2010;4:37-43.

3. Shaw LJ, Bugiardini R, Bairey Merz CN. Women and ischemic heart disease. J Am Coll Cardiol. 2009;54:1561-1575.

4. Wenger NK. Coronary heart disease: The female heart is vulnerable. Prog Cardiovasc Dis. 2003; 46(3):199-299.

5. Wilson PW, Kannel WB, Silbershatz H, D'Agostino RB. Clustering of metabolic factors and coronary heart disease. Arch Intern Med.1999;159:11041109.

6. Wilson PW, D'Agostino RB, Sullivan L, Parise H, and Kannel WB. Overweight and Obesity as Determinants of Cardiovascular Risk: The Framingham Experience. Archives of Internal Medicine. 2002;162:1867-1872.

7. Jacobs AK. Coronary intervention in 2009. Are women no different than men? Circ Cardiovasc Intervent. 2009;2:69-78

8. Berger JS, Elliott L, Gallup D, Roe M, Granger CB, Armstrong PW, et al. Sex differences in mortality following acute coronary syndromes. JAMA. 2009;302:874-82

9. Johnson BD, Shaw LJ, Pepine CJ, Reis SE, Kelsey SF, Sopko G, et al. Persistent chest pain predicts cardiovascular events in women without obstructive coronary artery disease: results from the $\mathrm{NIH}$ NHLBI-sponsored Women's Ischaemia Syndrome Evaluation (WISE) study. Eur Heart J 2006;27:14081415.

10. Shaw LJ, Merz CN, Pepine CJ, et al, for the WISE Investigators. The economic burden of angina in women with suspected ischemic heart disease: results from the National Institutes of HealthNational Heart, Lung, and Blood Institute sponsored Women's Ischemia Syndrome Evaluation. Circulation 2006;114:894-904.

11. Han SH, Bae JH, Lennon RJ, Eeckhout $\mathrm{E}$, Barsness GW, et al. Sex differences in atheroma burden and endothelial function in patients with early coronary atherosclerosis. Eur Heart J 2008;29:1359-1369.

12. Burke AP, Farb A, Malcom GT, Liang YH, et al. Effect of risk factors on the mechanism of acute thrombosis and sudden coronary death in women. Circulation. 1998; 97:2110.

13. Thygesen K, Alpert JS, et al. Third universal definition of myocardial infarction. European Heart Journal 2012; 33 2551-6713.

14. World Health Organization report on Noncommunicable Diseases in South-East Asian Region. 2006.

15. Shruthi B. Clinical Profile of Ischemic Heart Disease in Women with Special Reference to the Risk Factors. Sch. J. App. Med. Sci., 2014; 2(6C):30203025

16. The Seventh Report of the Joint National Committee on Prevention, Detection, Evaluation and Treatment of High Blood Pressure. 2003.

17. American Diabetes Association, Standard of Medical Care in Diabetes. The Journal of Applied Research and Education 2007; 40:455-498.

18. The Third Report of National Cholesterol Education Program (NCEP) Expert Panel on Detection, Evaluation, and Treatment of High Blood Cholesterol in Adults (Adult Treatment Panel 111). Circulation 2002; 106:3143-421.

19. Neeland SJ, Patel RS, Eshtehardi P, Dhawan S, Coronary angiographic scoring systems: an evaluation of their equivalence and validity. Am Heart J. 2012 Oct; 164(4): 547-552.

20. Gensini GG. A more meaningful scoring system for determining the severity of coronary heart disease. Am J Cardiol (1983) 51:606-610.

21. Joshi P, Isalm S, Pais P, Reddy S, Dorairaj P, et al. Risk Factorrs for early meycardial infarction in South Asians compared with individual in other countries. JAMA, 2007;297:286-294.

22. Manish S, Rajesh K, Surinder T, Rajeev B. Clinical Profile, Risk Factors and Short Term Outcome of Acute Myocardial Infraction in Females: A Hospital Based Study. Heart India 2013; 1(3): 73-77.

23. Chang WC, Kaul P, Westerhout CM, Graham MM, Fu Y, Chowdhury T, et al. Impact of sex on long-term mortality from acute myocardial infarction vs. 
unstable angina. Arch Intern Med. 2003;163: 2476-2484.

24. Yehia A, Amal J. Characteristics and Risk Factors Attributed to Coronary Artery Disease in Women Attended Health Services in Gaza-Palestine Observational Study. World Journal of Cardiovascular Diseases, 2015, 5, 9-18.

25. Huxley R, Barzi F, Woodward M. Excess Risk of Fatal Coronary Heart Disease Associated with Diabetes in Men and Women: Meta-Analysis of 37 Prospective Cohort Studies. British Medical Journal. 2006; 332, 73-78.

26. Spencer EA, Pirie KL, Stevens RJ. Million Women Study Collaborators Diabetes and Modifiable Risk Factors for Cardiovascular Disease: The
Prospective Million Women Study. European Journal of Epidemiology. 2008; 23, 793-799.

27. Jamee A, Abed Y, Jalambo. Gender Difference and Characteristics Attributed to Coronary Artery Disease in Gaza-Palestine. Global Journal of Health Science. 2013; 5: 51-56.

28. Yusuf S, Hawken S, Ounpuu S, Dans T, Avezum A, et al. INTERHEART Study Investigators. Effect of potentially modifiable risk factors associated with myocardial infarction in 52 countries (the INTERHEART study): case-control study. Lancet. 2004;364:937-952.

29. Gera S, Harsh W. Percutaneous coronary interventions: a clinical-angiographic study. JIACIM 2004; 5(4):322-326. 